\title{
SELECTIVE MITOCHONDRIAL ADENOSINE TRIPHOSPHATE-SENSITIVE POTASSIUM CHANNEL ACTIVATION IS SUFFICIENT TO PRECONDITION HUMAN MYOCARDIUM
}

Benjamin J. Pomerantz, MD

Thomas N. Robinson, MD

Todd D. Morrell, MD

Julie K. Heimbach, MD

Anirban Banerjee, $\mathrm{PhD}$

Alden H. Harken, MD
Objectives: Recently, the mitochondrial adenosine triphosphate-sensitive potassium channel has been suggested to be the final common effector of myocardial preconditioning. The purpose of this study is to determine whether selective mitochondrial adenosine triphosphate-sensitive potassium channel activation alone can precondition human myocardium from an ischemia/reperfusion insult.

Methods: Isolated human right atrial trabeculae were placed in tissue baths, paced, and subjected to 30 minutes of normothermic hypoxia (ischemia) followed by 45 minutes of reoxygenation (reperfusion). Trabeculae were preconditioned with a selective mitochondrial adenosine triphosphate-sensitive potassium channel opener (diazoxide $30 \mu \mathrm{mol} / \mathrm{L}$ ) or a nonselective purinergic agonist, adenosine $(125 \mu \mathrm{mol} / \mathrm{L})$, for 5 minutes (adenosine) followed by a 10-minute washout period. Developed force at end reperfusion (mean \pm standard error) was compared with baseline, and tissue creatine kinase and adenosine triphosphate levels were measured after ischemia/reperfusion.

Results: Trabeculae subjected to ischemia/reperfusion exhibited $30 \% \pm 2 \%$ of baseline developed force, whereas trabeculae subjected to selective adenosine triphosphate-sensitive potassium channel opening (diazoxide) and nonselective purinergic agonist (adenosine) recovered to $55 \% \pm 7 \%$ and $46 \% \pm 3 \%$ of baseline developed force, respectively. Tissue creatine kinase activity was preserved in both the diazoxide- and adenosine-treated trabeculae $(5.4 \pm 12$ and $5.4 \pm 14 \mu \mathrm{mol} / \mathrm{L}$ per gram wet tissue) compared with ischemia/reperfusion $(1.8 \pm 0.2 \mathrm{U} / \mathrm{mg}$ wet tissue $)$. Adenosine triphosphate levels at end reperfusion were also increased in the trabeculae treated with selective (diazoxide) and nonselective (adenosine) adenosine triphosphate-sensitive potassium channel opener $(4.1 \pm 0.01$ and $4.4 \pm 0.2 \mu \mathrm{mol} / \mathrm{L}$ per gram wet tissue) compared with trabeculae subjected to ischemia/reperfusion $(1.5 \pm 0.1 \mu \mathrm{mol} / \mathrm{L}$ per gram wet tissue $)$.

Conclusions: These results suggest that selective mitochondrial adenosine triphosphate-sensitive potassium channel activation preconditions human myocardium and the protection conferred is equal to that of adenosine preconditioning. Targeted openers of mitochondrial adenosine triphosphatesensitive potassium channels promote constructive protection of myocellular energy levels, contractile function, and cellular viability in human myocardium after ischemia/reperfusion. (J Thorac Cardiovasc Surg 2000;120:387-92)
From the Department of Surgery, University of Colorado Health Sciences Center, Denver, Colo.

Supported by National Institutes of Health Grants GM49222 and GM08315.

Received for publication Feb 1, 2000; revisions requested Feb 28, 2000; revisions received March 13, 2000; accepted for publication March 27, 2000.
Address for reprints: Benjamin J. Pomerantz, MD, Department of Surgery, Campus Box C-320, University of Colorado Health Sciences Center, 4200 East Ninth Ave, Denver, CO 80262 (Email: ben.pomerantz@uchsc.edu).

Copyright (C) 2000 by The American Association for Thoracic Surgery

$0022-5223 / 2000 \$ 12.00+0 \quad \mathbf{1 2 / 1 / 1 0 7 5 2 1}$

doi:10.1067/mtc.2000.107521 
$\mathrm{T}_{\mathrm{i} i \mathrm{~s}}$ ansient ischemia before a prolonged ischemic insult is recognized as providing protection. This phenomenon is termed ischemic preconditioning. ${ }^{1}$ Ischemic preconditioning has been demonstrated in numerous animals, ${ }^{2,3}$ as well as in human myocardium. ${ }^{4-6}$ Ischemic preconditioning improves postischemic functional recovery, reduces infarct area, increases coronary flow, and preserves cellular adenosine triphosphate (ATP) levels. ${ }^{2,7,8}$ In vivo ischemic preconditioning in human beings has been reported. In the Thrombosis in Myocardial Infarction (TIMI) 4 trial, prior angina conferred benefit on in-hospital outcome during an acute myocardial infarction. ${ }^{9}$ Attempts to use transient ischemia as a clinically accessible means of preconditioning human myocardium have been limited. Investigational use of ischemic preconditioning, however, has proven protective during coronary artery angioplasty and coronary artery bypass surgery. ${ }^{10-12}$ These studies reported a beneficial effect of ischemic preconditioning according to multiple outcome criteria. The routine use of ischemic preconditioning during routine coronary artery angioplasty and coronary bypass surgery has not become standard among clinicians.

The ATP-sensitive potassium $\left(\mathrm{K}_{\text {ATP }}\right)$ channel has been implicated in both ischemic and purinergic preconditioning of human myocardium. $5,13,14$ The $\mathrm{K}_{\text {ATP }}$ channel is present within the plasma, as well as the mitochondrial membranes. These channels can now be pharmacologically separated and interrogated with the use of selective agonists and antagonists. We and others ${ }^{5,14-17}$ have demonstrated that nonselective $\mathrm{K}_{\text {ATP }}$ channel blockade inhibits both ischemic and purinergic (adenosine) preconditioning in human myocardium. The mechanisms involved are not understood because of the broad effects of these agents. Nonselective $\mathrm{K}_{\text {ATP }}$ channel activation shortens the action potential, calcium currents are affected, and myocardial depression can occur. ${ }^{18,19}$ These untoward effects of nonselective $\mathrm{K}_{\text {ATP }}$ channel activation have prompted interrogation of targeted mitochondrial $\mathrm{K}_{\text {ATP }}$ channel openers as possible end effectors of myocardial preconditioning.

Garlid and associates ${ }^{20}$ reported that diazoxide, a selective mitochondrial $\mathrm{K}_{\text {ATP }}$ channel opener, preconditioned rat myocardium. Selective mitochondrial $\mathrm{K}_{\mathrm{ATP}}$ channel blockade abolished the protective effects of selective mitochondrial $\mathrm{K}_{\mathrm{ATP}}$ channel opening in rat myocardium. We hypothesized that targeted mitochondrial $\mathrm{K}_{\mathrm{ATP}}$ channel activation is sufficient to protect human myocardium against an ischemia/reperfusion (I/R) insult through preservation of cellular energy levels, contractile function, and cellular viability.

\section{Materials and methods}

Isolated atrial trabeculae. Right atrial trabeculae were obtained from patients during cannulation for cardiopulmonary bypass as previously described. ${ }^{14}$ The study was approved by the investigational review board of the University of Colorado Health Sciences Center.

Materials. Modified Tyrode solution was prepared daily with de-ionized distilled water $\left(\mathrm{ddH}_{2} \mathrm{O}\right)$ and consisted of the following (in millimoles per liter): D-glucose 5.0; $\mathrm{CaCl}_{2} 2.0$; $\mathrm{NaCl} 118.0 ; \mathrm{KCl} 4.0 ; \mathrm{MgSO}_{4} 7 \mathrm{H}_{2} \mathrm{O} 1.2 ; \mathrm{NaHCO}_{3} 25.0$; and $\mathrm{NaH}_{2} \mathrm{PO}_{4}$ 1.2. All reagents were obtained from Sigma Chemical Company (St Louis, Mo). The substrate-free Tyrode solution contained choline chloride $(7 \mathrm{mmol} / \mathrm{L})$ to maintain osmolarity. Diazoxide, a selective mitochondrial $\mathrm{K}_{\text {ATP }}$ channel opener (Sigma), was dissolved in dimethyl sulfoxide and then dissolved in Tyrode solution to a final concentration of $30 \mu \mathrm{mol} / \mathrm{L}$ in the organ bath. The final concentration of dimethyl sulfoxide was less than $1 \%$. Diazoxide is a selective $\mathrm{K}_{\text {ATP }}$ channel agonist. Differential effects of diazoxide are concentration dependent. The mitochondrial $\mathrm{K}_{\mathrm{ATP}}$ channel is 2000 times more sensitive to diazoxide than the sarcolemmal $\mathrm{K}_{\mathrm{ATP}}$ channel. ${ }^{21}$ The dose of diazoxide used in our protocol was determined by a dose-response experiment (data not shown) and is 1000-fold less than the published dose for nonselective $\mathrm{K}_{\mathrm{ATP}}$ channel activation. Adenosine, a nonselective purinergic agonist (Sigma), was dissolved in deionized water and then dissolved in Tyrode solution to a final concentration to $125 \mu \mathrm{mol} / \mathrm{L}$ in the organ bath.

Experimental design. Trabeculae were equilibrated for 90 minutes to allow stabilization of developed force. Trabeculae that failed to generate greater than $250 \mathrm{mg}$ of developed force were excluded from the study. Pacing was performed with platinum electrodes (Radnoti Glass, Inc, Monrovia, Calif) for field stimulation. The electrodes were placed on either side of the trabeculae and stimulated (Grass SD9 stimulator; Grass Instruments, Braintree, Mass) with 6ms pulses at a voltage $20 \%$ above threshold. Contractions were monitored by force transducers (Grass FT03) and recorded with a computerized preamplifier and digitizer (MacLab quad bridge, MacLab/8e, AD Instruments, Milford, Mass) and continuously monitored with a Macintosh computer (Apple Computer, Cupertino, Calif).

After equilibration, trabeculae were divided into 4 groups: (1) control, no ischemia $(\mathrm{n}=5)$; (2) I/R alone without a preconditioning stimulus $(n=6)$; (3) selective mitochondrial $\mathrm{K}_{\text {ATP }}$ channel activation (diazoxide) $(\mathrm{n}=7)$; and (4) nonselective purinergic activation (adenosine) $(\mathrm{n}=6)$. Preconditioned trabeculae were exposed to diazoxide 30 $\mu \mathrm{mol} / \mathrm{L}$ or adenosine $125 \mu \mathrm{mol} / \mathrm{L}$ for 5 minutes followed by a 10-minute washout period, before ischemia.

Groups 2,3, and 4 were challenged with a 30-minute period of simulated ischemia, which consisted of substrate-free hypoxic Tyrode buffer with pacing at $3 \mathrm{~Hz}$, followed by reperfusion to stable recovery of developed force (45 minutes) with normoxic Tyrode solution with pacing at $1 \mathrm{~Hz}$. Contractile function is reported as developed force in mil- 


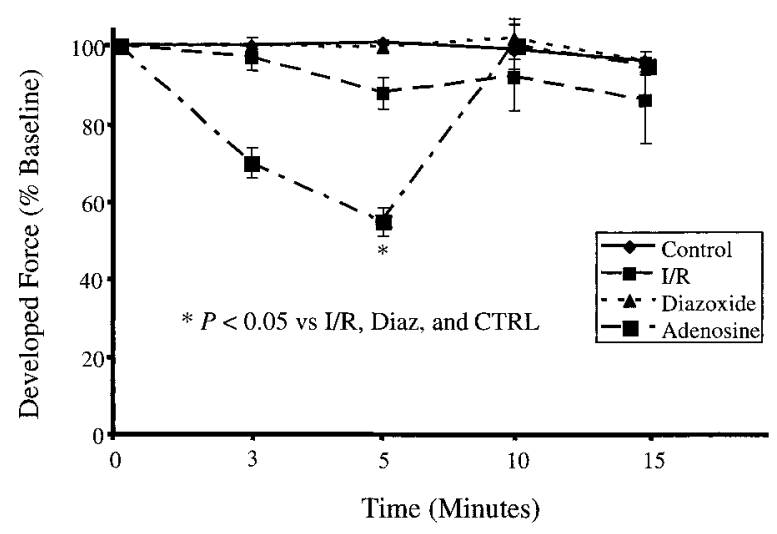

Fig 1. Selective (diazoxide) preconditioning did not demonstrate negative inotropic effects on trabeculae during the 5minute treatment period. This is in contrast to the trabeculae treated with adenosine, which did exhibit a decrease in developed force (55\% of baseline) during the preconditioning period. I/R, Ischemia/reperfusion; Diaz, diazoxide; CTRL, control.

ligrams. Developed force is reported as percent change from baseline.

Preserved trabecular tissue creatine kinase (CK) activity. End reperfusion tissue creatine kinase (CK) activity was determined as previously described. ${ }^{2}$ In brief, trabeculae were added to 100 volumes of cold isotonic extraction buffer consisting of imidazole acetate $(50 \mathrm{mmol} / \mathrm{L}), \mathrm{Mg}^{2+}$ acetate $(10 \mathrm{mmol} / \mathrm{L}), \mathrm{KH}_{2} \mathrm{PO}_{4}(4 \mathrm{mmol} / \mathrm{L})$, ethylenediaminetetraacetic acid $(2 \mathrm{mmol} / \mathrm{L}), N$-acetylcysteine $(0.05 \mathrm{mmol} / \mathrm{L})$, sulfur in $0.8 \%$ ethanol $(0.0125 \mathrm{mmol} / \mathrm{L})$, and sucrose $(250$ $\mathrm{mmol} / \mathrm{L}), \mathrm{pH}$ 7.6. Samples were homogenized with a tissue homogenizer (parallel blades $0.5 \mathrm{~cm}$ apart) at half maximal speed for 20 seconds (10 equally spaced bursts) followed by centrifugation at $2000 \mathrm{~g}$ for 5 minutes and $20,000 \mathrm{~g}$ for 10 minutes. The final supernatant was diluted to less than 0.25 absorbance units per minute. The assay was performed with Sigma diagnostic kit No. 47-UV on an automated spectrophotometer (Hewlett-Packard diode array spectrophotometer No. 8452; Hewlett-Packard Company, Andover, Mass) in cuvettes maintained at $30^{\circ} \mathrm{C}$. Samples and reagents were maintained at $4^{\circ} \mathrm{C}$ before assay. Results are presented as units of CK activity per gram wet weight of tissue.

Preserved tissue ATP content. End reperfusion tissue ATP levels were determined by means of trichloroacetic acid extraction and a luciferin-luciferase assay. In brief, trabeculae were suspended in $500 \mu \mathrm{L}$ of $10 \%$ trichloroacetic acid and homogenized with a vertishear tissue homogenizer (parallel blades $0.5 \mathrm{~cm}$ apart) at half maximal speed for 20 seconds (10 equally spaced bursts) followed by centrifugation at $5000 \mathrm{~g}$ for 10 minutes at $4^{\circ} \mathrm{C}$. The supernatant was decanted and diluted 1:250 with HEPES buffer to a final $\mathrm{pH}$ of 7.75. The assay was performed with the Analytical Luminescence Laboratory ATP detection kit, catalog No. 5000, on an automated luminometer (Monolight 3010; Analytical Luminescence Laboratory, San Diego, Calif). ${ }^{22}$

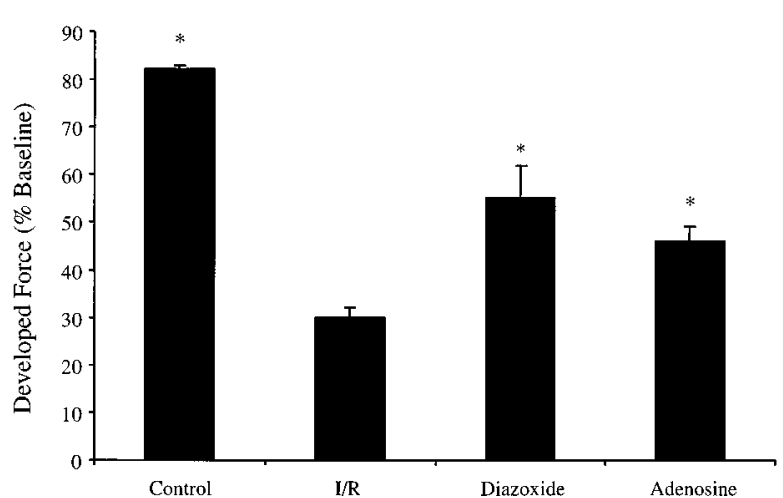

Fig 2. Selective mitochondrial $\mathrm{K}_{\mathrm{ATP}}$ channel (diazoxide) and nonselective purinergic preconditioning (adenosine) preconditioning in human atrial trabeculae. Preconditioning with both diazoxide and adenosine exhibit increased recovery of developed force relative to untreated trabeculae after ischemia/reperfusion (I/R). ${ }^{*} P<.05$ vs $\mathrm{I} / \mathrm{R}$ alone. Recovery in the adenosine and diazoxide groups did not return to that of the control trabeculae. Selective mitochondrial $\mathrm{K}_{\text {ATP }}$ (diazoxide) and purinergic (adenosine) recovery are not different.

Samples and reagents were maintained at $4^{\circ} \mathrm{C}$ before assay. Results are presented as micromoles per liter per gram wet weight of tissue.

Statistical analysis. All data are presented as mean \pm standard error. All values were compared by analysis of variance with application of a post hoc Bonferroni/Dunn test (StatView 5.0.1, SAS Institute, Inc, Cary, NC).

\section{Results}

Eighteen patients were included in this study. The baseline developed force and trabecular size were similar in all groups. Developed force is represented as percentage of baseline.

No loss in developed force was seen in the trabeculae treated with selective mitochondrial $\mathrm{K}_{\text {ATP }}$ channel activation (diazoxide) before the onset of ischemia. This is in contrast to preconditioning with a nonselective purinergic agonist (adenosine), where a decrease in developed force to $55 \% \pm 4 \%$ was seen during the preconditioning period and before the ischemic challenge. After washout of the adenosine, contractile function of the adenosine-preconditioned trabeculae returned to $99 \% \pm 6 \%$ of baseline. Recovery of contractile function after I/R was increased over I/R alone and was equal to that of adenosine preconditioning (Fig 1).

Preconditioning with mitochondrial $\mathrm{K}_{\mathrm{ATP}}$ channel opening and nonselective purinergic preconditioning improved post-I/R developed force compared with I/R alone (Fig 2). 


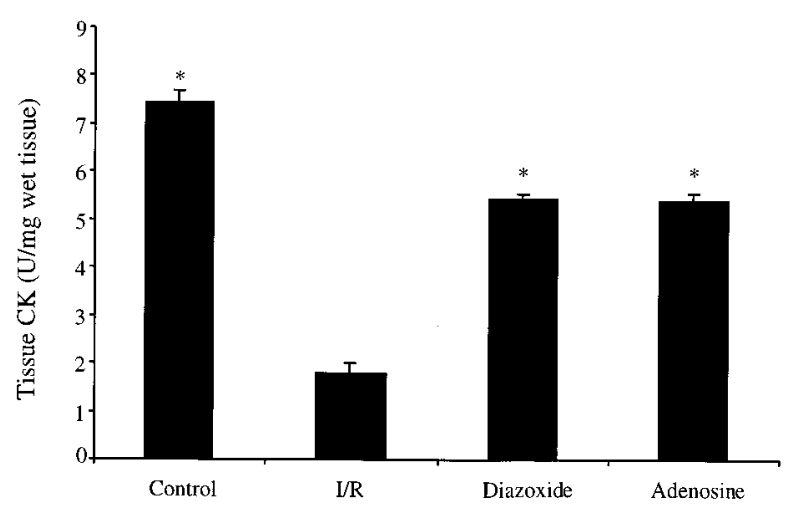

Fig 3. Tissue CK activity per gram wet weight of tissue after reperfusion. Preconditioning with diazoxide and adenosine preserved tissue $\mathrm{CK}$ activity ( ${ }^{*} P<.05$ vs I/R trabeculae), indicating less $\mathrm{CK}$ enzyme leak and enhanced tissue viability.

Tissue CK activity at end reperfusion was preserved in both the selective (diazoxide) and purinergic (adenosine) preconditioning trabeculae. The CK activity remaining after the ischemic challenge in the I/R alone group was $1.7 \pm 0.2$ units of activity per gram of wet tissue weight. This is in contrast to the CK activity present in the trabeculae preconditioned with diazoxide and adenosine, which contained $5.4 \pm 14$ and $5.4 \pm 12$ units of CK activity per gram wet myocardium $(P<.05$ vs I/R alone). CK activity in control trabeculae, perfused and paced for the length of the experiment without undergoing $\mathrm{I} / \mathrm{R}$, was $7.4 \pm 0.25$ units per gram wet tissue (Fig 3).

Cellular energy levels as represented by post-I/R cellular ATP levels are depicted in Fig 4. The post-I/R ATP level in trabeculae preconditioned with selective mitochondrial $\mathrm{K}_{\mathrm{ATP}}$ channel activation (diazoxide) was $4.1 \pm 0.1 \mu \mathrm{mol} / \mathrm{mg}$ wet tissue $(P<.05$ vs $\mathrm{I} / \mathrm{R}$ alone). The ATP level in trabeculae after preconditioning with adenosine was $4.4 \pm 0.2 \mu \mathrm{mol} / \mathrm{mg}$ wet tissue $(P<.05$ vs $\mathrm{I} / \mathrm{R}$ alone). The ATP level in trabeculae subjected to I/R alone was $1.5 \pm 0.1 \mu \mathrm{mol} / \mathrm{mg}$ wet tissue. The ATP level in trabeculae in the nonpreconditioned, nonischemic control group was $5.1 \pm$ $0.1 \mu \mathrm{mol} / \mathrm{mg}$ wet tissue.

\section{Discussion}

The findings of this study are as follows: (1) Selective mitochondrial $\mathrm{K}_{\mathrm{ATP}}$ channel opening provides functional protection against a simulated I/R injury; (2) nonselective purinergic receptor activation before a simulated I/R injury also provides functional protection against the I/R injury; (3) post-I/R cellular energy lev-

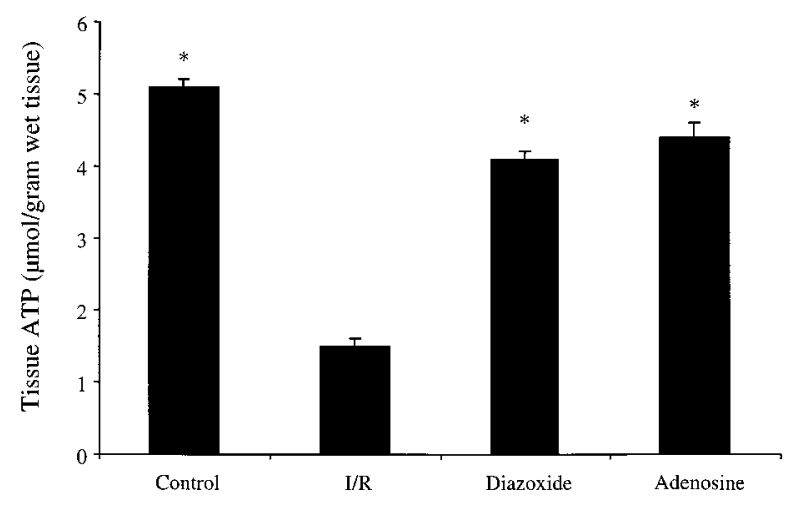

Fig 4. Cellular energy levels after I/R. Selective (diazoxide) and nonselective purinergic preconditioning increase post-I/R cellular ATP levels. ( ${ }^{*} P<.05$ vs I/R alone). Preconditioning with either diazoxide or adenosine did not restore cellular energy levels to those of untreated control trabeculae.

els are preserved; and (4) selective mitochondrial $\mathrm{K}_{\mathrm{ATP}}$ channel opening preserves cellular viability after an I/R injury after preconditioning with selective mitochondrial $\mathrm{K}_{\text {ATP }}$ channel activation in human myocardium. These results demonstrate the ability to selectively precondition human myocardium by directly accessing the mitochondrial $\mathrm{K}_{\mathrm{ATP}}$-sensitive channel.

These results provide evidence that the mitochondrial $\mathrm{K}_{\text {ATP }}$ channel is an effector of preconditioning in human myocardium. Previous studies from our laboratory have implicated the $\mathrm{K}_{\text {ATP }}$ channel as an end effector of both purinergic and transient ischemic preconditioning in human myocardium. 5,14 No previous reports in human beings have examined preconditioning stimuli specific to the mitochondrial $\mathrm{K}_{\mathrm{ATP}}$ channel. Other investigators have examined the involvement of the mitochondrial $\mathrm{K}_{\mathrm{ATP}}$ channel in myocardial preconditioning of various animals/tissues. ${ }^{23,24}$ Our results support the observations of Garlid and associates, ${ }^{20}$ who first presented the cardioprotective effect of selective mitochondrial $\mathrm{K}_{\text {ATP }}$ channel openers using reconstituted heart mitochondria and isolated rat hearts.

In addition to an improvement in postischemic developed force, we observed an increase in postischemic cellular ATP levels and tissue CK activity with selective mitochondrial $\mathrm{K}_{\mathrm{ATP}}$ channel activation (diazoxide). We postulate that the positive impact on cellular viability and cellular energetics is the mechanism by which direct mitochondrial $\mathrm{K}_{\mathrm{ATP}}$ channel activation protects human myocardium.

$\mathrm{We}^{5,14}$ and others ${ }^{16,18,24}$ have previously implicated the nonselective involvement of the $\mathrm{K}_{\text {ATP }}$ channel in preconditioning of human myocardium. Recently, 
other investigators have interrogated the selective role of sarcolemmal as distinct from the mitochondrial potassium channel. When the plasma membrane $\mathrm{K}_{\text {ATP }}$ channel is activated, a change in the action potential is seen that is thought to be due to a change in calcium handling. ${ }^{25}$ This altered action potential is not apparent with activation of the mitochondrial $\mathrm{K}_{\mathrm{ATP}}$ channel. In our study, no change in the action potential or in the trabecular contraction profile was seen, implying no "spillover" involvement of the sarcolemmal $\mathrm{K}_{\text {ATP }}$ channel with our dose of diazoxide.

Preconditioning with selective mitochondrial $\mathrm{K}_{\text {ATP }}$ channel opening and with adenosine were both effective in preserving developed force, cellular viability, and cellular energy levels. A brief decrease in developed force was noted with purinergic preconditioning during the 5-minute treatment period, emphasizing the advantage of a targeted preconditioning strategy. The developed force returned to baseline, however, after the washout of adenosine during the 10 minutes of perfusion before the onset of ischemia. This is in contrast to selective mitochondrial $\mathrm{K}_{\mathrm{ATP}}$ channel activation, where there was no loss of developed force during the treatment period. The adenosine-mediated decrease in contractile force observed in our study is consistent with other studies in which a similar decrease in contractile force has been described. ${ }^{5,25}$

Diazoxide is currently in clinical use for noncardioprotective indications. Diazoxide, a thiazide derivative, has antihypertensive effects that are profound and have a rapid onset. Diazoxide also provokes secondary effects when given at the standard antihypertensive dose and when given for prolonged periods. These include hyperglycemia, hirsutism, and water and electrolyte retention. In the present study, no negative inotropic effects were associated with diazoxide administration. These side effects should not be clinically observable if diazoxide is used in a single dose for myocardial preconditioning. A potential concern in using a direct mitochondrial agent is its ability to provide comprehensive preconditioning in vivo. It is possible that by using a receptor-based form of preconditioning, adenosine may more directly activate signaling pathways within the myocyte. The standard dose of diazoxide used clinically $(17.9 \mu \mathrm{g} / \mathrm{mL})$ is more than twice the dose necessary to precondition myocardium $(6.9 \mu \mathrm{g} / \mathrm{mL})$, emphasizing that clinical use of diazoxide for myocardial preconditioning should be safe.

Pharmacologic targeting of the mitochondrial $\mathrm{K}_{\mathrm{ATP}}$ channel may permit constructive cardiac preconditioning clinically without the untoward sequelae of nonselective $\mathrm{K}_{\mathrm{ATP}}$ channel activation.

\section{REFERENCES}

1. Murry CE, Jennings RB, Reimer KA. Preconditioning with ischemia: a delay of lethal cell injury in ischemic myocardium. Circulation 1986;74:1124-36.

2. Banerjee A, Locke-Winter C, Rogers KB, et al. Preconditioning against myocardial dysfunction after ischemia and reperfusion by an alpha 1-adrenergic mechanism. Circ Res 1993;73:656-70.

3. Mitchell MB, Winter CB, Banerjee A, Harken AH. The relationship between ischemia-reperfusion injury, myocardial stunning and cardiac preconditioning. Surg Gynecol Obstet 1993;177:97-114.

4. Yellon DM, Alkhulaifi AM, Pugsley WB. Preconditioning the human myocardium. Lancet 1993;342:276-7.

5. Cleveland JC Jr, Meldrum DR, Rowland RT, Banerjee A, Harken $\mathrm{AH}$. Adenosine preconditioning of human myocardium is dependent upon the ATP-sensitive $\mathrm{K}^{+}$channel. J Mol Cell Cardiol 1997;29:175-82.

6. Cleveland JC Jr, Wollmering MM, Meldrum DR, et al. Ischemic preconditioning in human and rat ventricle. Am J Physiol 1996;271:H1786-94.

7. Yellon DM, Baxter GF, Garcia-Dorado D, Heusch G, Sumeray MS. Ischaemic preconditioning: present position and future directions. Cardiovasc Res 1998;37:21-33.

8. Carr CS, Grover GJ, Pugsley WB, Yellon DM. Comparison of the protective effects of a highly selective ATP-sensitive potassium channel opener and ischemic preconditioning in isolated human atrial muscle. Cardiovasc Drugs Ther 1997;11:473-8.

9. Kloner RA, Shook T, Przyklenk K, et al. Previous angina alters in-hospital outcome in TIMI 4. A clinical correlate to preconditioning? [see comments]. Circulation 1995;91:37-45.

10. Szmagala P, Morawski W, Krejca M, Gburek T, Bochenek A. Evaluation of perioperative myocardial tissue damage in ischemically preconditioned human heart during aorto coronary bypass surgery. J Cardiovasc Surg (Torino) 1998;39:791-5.

11. Lu EX, Chen SX, Yuan MD, et al. Preconditioning improves myocardial preservation in patients undergoing open heart operations [see comments]. Ann Thorac Surg 1997;64:1320-4.

12. Deutsch E, Berger M, Kussmaul WG, Hirshfeld JW Jr, Herrmann HC, Laskey WK. Adaptation to ischemia during percutaneous transluminal coronary angioplasty: clinical, hemodynamic, and metabolic features [see comments]. Circulation 1990;82:2044-51.

13. Miura T, Tsuchida A. Adenosine and preconditioning revisited. Clin Exp Pharmacol Physiol 1999;26:92-9.

14. Cleveland JC Jr, Meldrum DR, Cain BS, Banerjee A, Harken AH. Oral sulfonylurea hypoglycemic agents prevent ischemic preconditioning in human myocardium: two paradoxes revisited. Circulation 1997;96:29-32.

15. Speechly-Dick ME, Grover GJ, Yellon DM. Does ischemic preconditioning in the human involve protein kinase $\mathrm{C}$ and the ATPdependent $\mathrm{K}^{+}$channel? Studies of contractile function after simulated ischemia in an atrial in vitro model. Circ Res 1995;77:1030-5

16. Gross GJ, Auchampach JA. Blockade of ATP-sensitive potassium channels prevents myocardial preconditioning in dogs. Circ Res 1992;70:223-33.

17. Qian YZ, Levasseur JE, Yoshida K, Kukreja RC. KATP channels in rat heart: blockade of ischemic and acetylcholine- mediated preconditioning by glibenclamide. Am J Physiol 1996;271:H23-8. 
18. Grover GJ, Newburger J, Sleph PG, et al. Cardioprotective effects of the potassium channel opener cromakalim: stereoselectivity and effects on myocardial adenine nucleotides. J Pharmacol Exp Ther 1991;257:156-62.

19. McPherson CD, Pierce GN, Cole WC. Ischemic cardioprotection by ATP-sensitive $\mathrm{K}^{+}$channels involves high- energy phosphate preservation. Am J Physiol 1993;265:H1809-18.

20. Garlid KD, Paucek P, Yarov-Yarovoy V, et al. Cardioprotective effect of diazoxide and its interaction with mitochondrial ATPsensitive $\mathrm{K}^{+}$channels: possible mechanism of cardioprotection. Circ Res 1997;81:1072-82.

21. Garlid KD, Paucek P, Yarov-Yarovoy V, Sun X, Schindler PA. The mitochondrial KATP channel as a receptor for potassium channel openers. J Biol Chem 1996;271:8796-9.
22. DeLuca M. Methods in enzymology. In: DeLuca M, editor. New York: Academic Press; 1978

23. Liu Y, Sato T, O'Rourke B, Marban, E. Mitochondrial ATPdependent potassium channels: Novel effectors of cardioprotection? Circulation 1998;97:2463-9.

24. Auchampach JA, Grover GJ, Gross GJ. Blockade of ischaemic preconditioning in dogs by the novel ATP dependent potassium channel antagonist sodium 5-hydroxydecanoate. Cardiovasc Res 1992;26:1054-62.

25.Bohm M, Pieske B, Ungerer M, Erdmann E. Characterization of $\mathrm{A} 1$ adenosine receptors in atrial and ventricular myocardium from diseased human hearts. Circ Res 1989;65:1201-11. 